\title{
Rosa e Gabriel entre o litoral e o interior do Brasil na Primeira República
}

Rosa and Gabriel between the coast and the interior of Brazil in the First Republic

Paulo Roberto de Oliveira (1)

(1) Universidade Federal de Ouro Preto

\section{Abstract}

The city of Uberaba, in the Triângulo Mineiro, Minas Gerais, played an important role in the intermediation of commerce that during the First Republic took place between the coffee economy of São Paulo and the interior of Brazil. This intermediation had as protagonists uberabenses that, in different forms, fit in that commercial circuit; many of whom owned businesses that stretched north to south, going from the interior to the coast and, in some cases, to the European continent. This article aims to follow the developments of some of these commercial networks, focusing on two important actors: Rosa Maria de Oliveira and Gabriel Orlando Teixeira Junqueira.

\section{Keywords}

trade, urbanization, modernization, First Republic, interior of Brazil.

JEL Codes N76, N96.

\section{Resumo}

A cidade de Uberaba, no Triângulo Mineiro, Minas Gerais, possuiu papel importante na intermediação do comércio que, durante a Primeira República, se realizou entre a economia cafeeira paulista e o interior do Brasil. Essa intermediação tinha como protagonistas uberabenses que de diferentes formas se enquadravam naquele circuito comercial; muitos desses possuiam negócios que se estendiam em direção ao norte e ao sul, indo do interior até o litoral e, em alguns casos, até o continente europeu. Este artigo tem como objetivo acompanhar os desdobramentos de algumas dessas redes comerciais, focando em dois atores importantes: Rosa Maria de Oliveira e Gabriel Orlando Teixeira Junqueira.

\section{Palavras-chave}

comércio, urbanização, modernização, Primeira República, interior do Brasil.

Códigos JEL N76, N96. 


\section{Introdução}

No final do século XIX, na travessia do Império à República, a economia brasileira passou por um significativo momento de expansão para dentro. $O$ principal lócus dessa expansão, mas não o único, foi o estado de São Paulo com o complexo cafeeiro, que, após disputas com outras economias regionais, conseguiu trazer para a sua órbita grande parte do interior do Brasil (Oliveira, 2014). Uma das principais ferramentas que forjaram essas ligações foi o setor de transportes paulista, o qual se desdobrava em diferentes direções.

Em 1888, o desdobramento desse setor rumo aos sertões alcançou a cidade de Uberaba, no Triângulo Mineiro, por meio da Companhia Mogiana de Estradas de Ferro ${ }^{1}$. Uberaba, já àquela altura, era uma cidade importante, com destaque na ligação entre o litoral e o sertão. Mesmo antes da constituição do complexo cafeeiro paulista, a cidade mineira já se destacava pelo papel de intermediação comercial. No final do século XIX esse papel se potencializou com a expansão da economia cafeeira.

Nesse contexto, o objetivo deste artigo é compreender a ligação de Uberaba ao complexo cafeeiro paulista e analisar o papel da cidade naquele momento como intermediadora entre a economia exportadora que se desenvolveu em São Paulo, por um lado, e o interior do Brasil, por outro. Esse processo será acompanhado por meio da atuação de personagens que alcançaram grande relevância nesse contexto e que possuíram importante papel como engrenagens desse circuito comercial.

Assim, as primeiras partes deste artigo abordarão os aspectos mais gerais do processo de modernização de Uberaba, para após isso, abrir espaço para a atuação de Rosa Maria de Oliveira e Gabriel Orlando Teixeira Junqueira.

\section{Uberaba entre o litoral e o sertão}

No início da Primeira República a região de Uberaba não poderia ser caracterizada como uma grande produtora de café, contudo, seus rumos, já no final do Império, ligavam-se à rubiácea, cultivada em maior intensidade ao sul do Rio Grande, em terrenos paulistas. A cidade de Uberaba, tal qual o Triângulo Mineiro, há muito possuía relações com São Paulo.

1 Doravante abreviada como CMEF, ou referida simplesmente como Mogiana. 
Foi nos tempos coloniais, com a expansão bandeirante em busca de ouro, que a região do atual Triângulo Mineiro estabeleceu relações estreitas com o que ao final do século XIX seria o estado de São Paulo. A integração de fato dessa região ao Império Português ocorreu no século XIX, quando Bartolomeu Bueno, o Anhanguera, descobriu ouro no interior de Goiás. A partir de então abriu-se o Caminho do Anhanguera, como passou ser conhecido, cruzando a região onde mais tarde se instalaria a cidade de Uberaba e concretizando-se como rota frequente para quem buscava atingir as minas goianas (Bacellar; Brioschi, 1999).

A princípio, o Triângulo Mineiro, assim com os terrenos goianos, esteve sob a jurisdição da capitania bandeirante. Mais tarde, os paulistas perderam o predomínio sobre aqueles terrenos. Desmembrado, o Triângulo Mineiro foi incorporado a Goiás até o século XIX, quando, enfim, passou a fazer parte de Minas Gerais. Já então, a região onde nasceria Uberaba seguia a sua vocação de interligação entre dois mundos, na interface entre o interior e o litoral (Rezende, 1991).

No final do século XIX, Uberaba já se destacava como a cidade mais importante da região, sobrepondo-se ao seu distrito de Uberabinha, futura Uberlândia, e a Araguari, cidade avançada na fronteira norte do Triângulo.

\section{Mapa 1 Localização de Uberaba entre a economia paulista e o mercado interior}

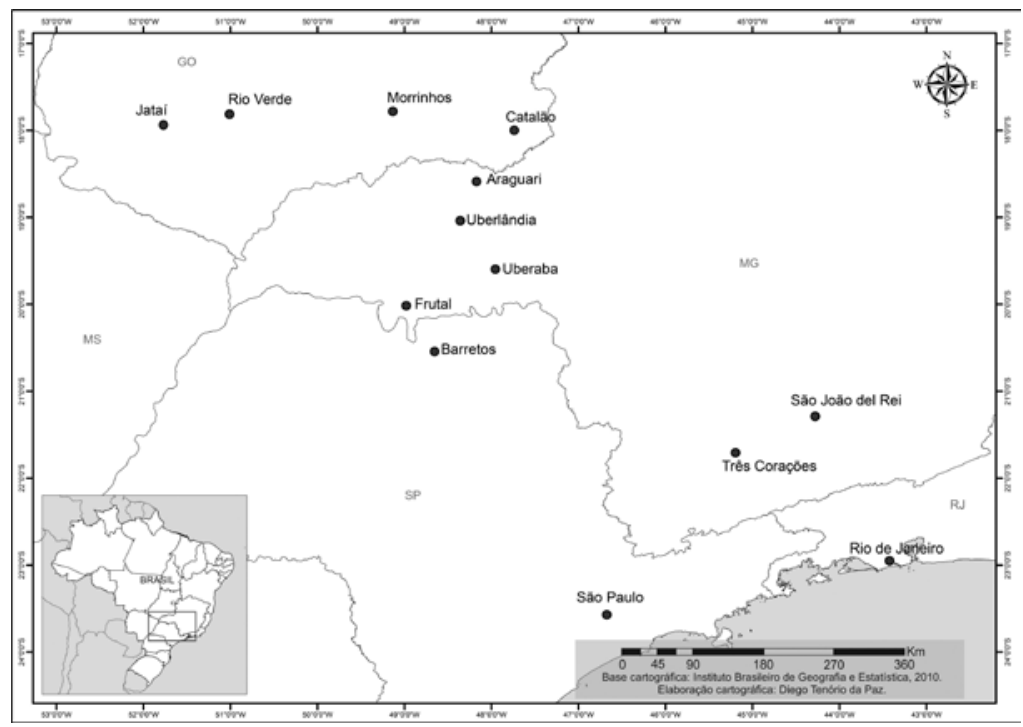

Fonte: Elaborado por Diego Tenório da Paz. 
No penúltimo ano do Império, Uberaba foi alcançada pelo desdobramento do setor de transportes paulista com a chegada da Companhia Mogiana de Estradas de Ferro à cidade. A chegada da CMEF até lá não se deu sem percalços. As ferrovias de São Paulo, apesar de não poderem ser simplesmente descritas como ferrovias do café - em alguns momentos serviram diferentes regiões e transportaram outras importantes mercadorias, como o gado -, surgiram ligadas à produção do café e à diversificação da economia cafeeira (Saes, 1981).

Vindo do Rio de Janeiro, o café adentrou terrenos paulistas pelo Vale do Paraíba, a partir de onde sua produção se desdobrou, seguindo no encalço das manchas de terra roxa, propícias ao seu cultivo. Durante a sua trajetória, a economia a princípio baseada no café se diversificou. A mão de obra foi paulatinamente substituída, da escrava para a livre, mas não necessariamente assalariada (Martins, 1979; Faleiros, 2010). Constituiu-se nesse processo o complexo cafeeiro paulista, baseado nos seguintes pilares:

a) a atividade produtora de café;

b) a agricultura produtora de alimentos e matérias-primas;

c) a atividade industrial;

d) a implantação e desenvolvimento do sistema ferroviário paulista;

e) a expansão do sistema bancário;

f) a atividade do comércio de importação e exportação;

g) o desenvolvimento da atividade criadora de infraestrutura;

h) a atividade do Estado, tanto o governo federal como o estadual, principalmente pela ótica do gasto público (Cano, 1977).

Parte de um complexo econômico, esses pontos se articulavam. O setor de transporte era estratégico. Em primeiro lugar, tornava possível a expansão da lavoura para regiões onde esta seria inviável se continuasse a contar com os meios de transporte tradicionais (Mello, 1998, p. 93). Servia, além disso, como mais um negócio lucrativo ligado ao café, sobretudo porque contava com incentivos governamentais por meio da garantia de juros (Matos, 1974, p. 55). Assim, a ferrovia era negócio atrativo ao ter a sua rentabilidade garantida. Outro ponto que tornava esse componente do complexo cafeeiro tão importante diz respeito à agricultura produtora de alimentos e matérias-primas. Era necessário que a economia paulista garantisse para si o suprimento de alimentos, visando à reprodução da mão de obra a preços razoáveis ${ }^{2}$ e, mais que isso, para que essa produção colocou como um dos pontos fundamentais para o desenvolvimento da economia cafeeira a 
sustentasse uma população que passava do campo para a cidade, de potenciais produtores de alimentos para consumidores (Camargo, 1952).

Além disso, a indústria em expansão necessitava de suprimentos constantes, entre eles a carne, item que alcançou grande importância nas primeiras décadas republicanas. Os administradores do estado de São Paulo buscaram a diversificação da agricultura paulista para o abastecimento da sua população em expansão; contudo, cientes de suas limitações, apoiaram o desdobramento de seu setor de transportes para além das suas fronteiras visando à busca de itens em outras regiões que não eram capazes de produzir nas proporções necessárias. ${ }^{3}$

\section{Mapa 2 Companhia Mogiana de Estradas de Ferro em 1970 - linha-tronco e ramais}

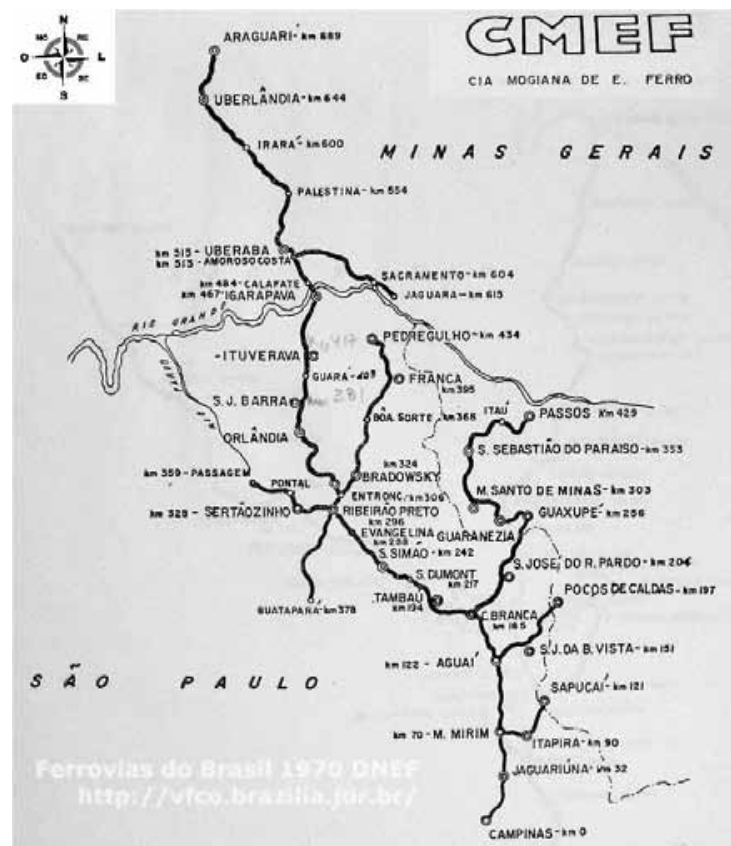

Fonte: <http://vfco.brazilia.jor.br/ferrovias/mapas/1970ciaMogiana.shtml>. Acesso em: 26 jan. 2018.

oferta de alimentos a preços aceitáveis. Contudo, a produção de alimentos à qual se referiu era a que ocorria dentro das fronteiras do estado de São Paulo, o que vai ao encontro da análise baseada na criação de um complexo econômico, desenvolvida à mesma época por Wilson Cano. Ver: MELLO, 1998.

3 Sobre a busca de alimentos no interior por meio do sistema de transportes paulista, ver: OLIVEIRA, 2014. Acerca da diversificação da economia cafeeira e seus limites, ver, além da tese citada: TOSI; FALEIROS, 2011; SAES; FONTANARI; OLIVEIRA, 2016. 
Foi nesse contexto que foi criada, em 1876, a Companhia Mogiana de Estradas de Ferro. Desde sua fundação, essa ferrovia de capital nacional possuía ambições que ultrapassavam o café, apesar de sua dependência com relação à receita proveniente da rubiácea. Seus planos incluíam a extensão rumo ao norte, no leito da Estrada do Anhanguera, ultrapassando as fronteiras paulista, mineira e goiana e seguindo em busca de produtos fornecidos pelos sertões e também do mercado consumidor em potencial constituído por eles (Pessoa Júnior, 1886, p. 383). Em sua marcha, a Mogiana teve que superar uma série de obstáculos, como a concorrência da Companhia Paulista de Estradas de Ferro, as disputas regionais que influenciaram a expansão de sua linha, a crise da década de 1890, que causou a mudança da estratégia da Companhia e a forçou a concentrar seus esforços nas áreas mineiras do Sul e Sudoeste do estado, produtoras de gado e café, entre outros. ${ }^{4}$

Há de se ressaltar que a economia paulista não se impôs pura e simplesmente às regiões que alcançou. Havia interesses de grupos locais que buscavam ligar-se a essa economia ou potencializar a sua ligação, em busca dos ganhos que os investimentos paulistas e a abertura de novo mercado que absorveria as mercadorias por eles produzidas poderiam render-lhes. Os habitantes de Goiás, por exemplo, como produtores de bens que poderiam servia a São Paulo, constantemente se debatiam com a necessidade de ligarem-se de maneira mais eficaz à economia paulista (Oliveira, 2014). Já os uberabenses, intermediadores dessa ligação, preocupavam-se constantemente com a sua expansão comercial e com maneiras de tornar mais efetivas as suas conexões para o norte e para o sul.

\section{Urbanização e modernização em Uberaba na aurora republicana}

A Primeira República brasileira trouxe consigo a expectativa de grandes mudanças e de "atualização" do Brasil frente às potências mundiais, sobretudo os Estados Unidos. Em sua primeira constituição republicana, os

4 A crise da década de 1890 tornou a expansão ferroviária muito mais cara, devido à depreciação da moeda nacional. Como muitos suprimentos usados pelas companhias ferroviárias eram importados, as empresas passaram a ter que despender muito mais pelos objetos necessários para a continuidade do crescimento de suas linhas. 
brasileiros inspiraram-se abertamente no país norte americano e buscaram implementar nessas plagas a mesma lógica institucional que guiava os anglo-saxões. Assim, o Brasil, republicano, tornou-se Estados Unidos do Brasil (Carvalho, 1997). Na passagem do século XIX para o XX elevou-se a expectativa de criação de um país urbano, onde as cidades se sobrepusessem aos sertões (Arruda, 2000).

Já no início do século XX o complexo cafeeiro paulista ultrapassou as fronteiras do estado e seguiu via caminhos de terras e de ferro em diferentes direções. Nos estados com os quais o complexo ligava-se, era fácil constatar a influência que o café exercia sobre as áreas não cafeeiras, como o Triângulo Mineiro, as regiões sul de Goiás, Minas Gerais e Mato Grosso. Para o norte, calçando com dormentes a Estrada do Anhanguera, cruzava o Triângulo Mineiro rumo ao estado de Goiás, empreendimento que seria concretizado pela $\mathrm{EFG}^{5}$, criada para integrar terras goianas à economia do atual Sudeste. Impossibilitada de seguir o seu avanço rumo ao norte devido à crise da década de 1890, a Companhia Mogiana de Estradas de Ferro cedeu a sua concessão à Estrada de Ferro Goiás, a qual assumiu a incumbência de estender os trilhos até a capital goiana (Borges, 1989).

Entre a economia interna e a economia exportadora, Uberaba passou por um processo de transformações que não era estranho a outras cidades brasileiras que assistiam à tentativa de propagação e imposição de uma moral burguesa que visava pautar a construção do espaço público e as relações sociais. Em muitos locais esse ímpeto modernizante esbarrou nas condições financeiras dos municípios. Mesmo antes, no Império, os municípios padeciam de rendas que permitissem que eles organizassem os seus serviços de maneira satisfatória (Franco, 1997, p. 128-152). Destarte, dependeram, em muitas regiões, da atuação de potentados locais que thes ofereciam as verbas necessárias para o estabelecimento de serviços mínimos. Com a República, a princípio, pouco mudou.

As principais preocupações dos uberabenses na aurora republicana voltavam-se para os melhoramentos e o controle do espaço urbano e para a manutenção de estradas que serviriam ao comércio que por ali passava, protegendo-o ou incentivando-o. Assim, uma das primeiras discussões, ainda ao ocaso do período imperial, dizia respeito à necessidade de aumento de praças para o policiamento da cidade. O número de praças exis- 
tentes era descrito como insuficiente, principalmente com a chegada da ferrovia e com a grande imigração que deveria dirigir-se para a cidade. ${ }^{6}$ A preocupação com a manutenção do espaço público também era notória. Ponto de passagem de gado, a cidade que queria apresentar-se como moderna não poderia mais conviver com boiadas cruzando suas ruas. ${ }^{7}$

Entre as mudanças pelas quais a cidade passava estava a reparação da Rua Barão Ataliba Nogueira, vista como importante por ser aquela que ligava o centro da cidade à estação da CMEF, prestes a ser inaugurada a rua era assim nomeada em homenagem ao diretor da ferrovia. Ela já havia passado por reparos, feitos pelo engenheiro Pedro José Versiani, sem que o município tivesse que pagar a conta. Em retribuição, o engenheiro recebeu ofício de agradecimento da Câmara em 25 de fevereiro de 1889, com pedido para que continuasse a auxiliar nos reparos urgentes a serem realizados antes da inauguração da estação e com nota de pesar pela sua mudança para Campinas, que aconteceria em breve. Era o mundo privado tomando o lugar do município carente de rendas. ${ }^{8}$

As preocupações com a mesma rua não ficaram nesses quesitos. Também foi determinado que a água do córrego que passava por ela fosse encanada e que os moradores caiassem suas fontes. ${ }^{9}$ A preocupação com a água revelada nas fontes se colocava em consonância com as tentativas de construção e normatização do espaço público. Em diferentes cidades, a água se tornou algo a ser regulamentado. Essa regulamentação estava atrelada ao espaço urbano e sua nova configuração, mas também ao aproveitamento econômico. São recorrentes nas falas dos administradores do estado de Minas Gerais as ações para utilizar as quedas d'agua para a geração de energia elétrica. ${ }^{10}$

No final do século XIX, em 1898, foram autorizados os estudos para o abastecimento de água em Uberaba pelo intendente municipal Gabriel Orlando Teixeira Junqueira por meio da Lei Municipal N. 91, de 8 de junho de

6 Atas da Câmara Municipal de Uberaba, 13/10/1887, doravante abreviadas como ACMU.

7 ACMU, 18 /01/1888. Segundo Restituti (2006, p. 91), desde meados do século XIX constatou-se a passagem de gado, vindo das regiões centrais do Brasil, pela cidade de Uberaba.

8 ACMU, 25/02/1889.

9 ACMU, $25 / 02 / 1889$.

10 Por exemplo, na Mensagem do Presidente de Estado de Minas Gerais de 1908, há a preocupação com o incentivo aos municípios para que aproveitassem as suas fontes de energia hidráulica com o objetivo de desenvolver as "indústrias". Mensagem do Presidente de Estado de Minas Gerais, 1908, p. 17. 
1898 (Bilharinho, 2007, p. 163). Uma empresa para esse fim foi organizada por um membro da câmara municipal, o vereador José de Oliveira Ferreira. ${ }^{11}$ José de Oliveira Ferreira possuía diferentes negócios em conjunto com sua esposa, Rosa Maria de Oliveira. O principal deles era a criação de gado em Mato Grosso. Ambos também eram sócios da empresa que levou a iluminação pública à cidade, como será analisado no próximo tópico.

A moldagem do espaço urbano às expectativas dos dirigentes republicanos do município estendia-se à reforma do mercado municipal e do lazareto. Não era suficiente reformar o espaço público pela lógica houssmaniana ${ }^{12}$ presente em outras importantes cidades brasileiras. Mais que isso, era preciso controlá-lo. Para tanto, era fundamental a propagação de uma moral que valorizasse o trabalho - parte integrante da concepção burguesa de mundo. Ainda no final do século XIX, em 1894 (1o de abril) os administradores do município traçaram estratégias para o controle da mão de obra estrangeira que seguia até lá sobre os trilhos da CMEF.

A preocupação dos membros da Câmara Municipal uberabense com o ócio colocava-se nesse quadro, mas também em intersecção com outro, qual seja, o da necessidade de controlar os grandes contingentes humanos que "emergiam" após o fim da escravidão. Não é por acaso que as autoridades das cidades como o Rio de Janeiro preocupavam-se com o controle da mão de obra educando-a para a substituição do botequim pelas habitações burguesas ou do cabaré pelo lar. ${ }^{13}$

As transformações pelas quais passava Uberaba denotam uma integração da cidade a um contexto mais amplo, em uma lógica criada pela segunda Revolução Industrial e que, por navios e trilhos, se espraiava por grande parte do globo, transformando a face de diferentes cidades brasileiras (Sevcenko, 2006). Eram mudanças que não se caracterizavam somente por aspectos econômicos, mas também simbólicos. Para os dirigentes de Uberaba, assim como para outros de cidades como Ribeirão Preto (SP) ou

11 Inventário de Rosa Maria de Jesus, Uberaba, 1920. APU, Segundo Ofício, caixa 339.

12 Georges-Eugène Haussmann foi o responsável pela grande reforma de Paris, a qual teve como objetivo tornar moderna aquela cidade, livrando-a dos traços medievais característicos. No Brasil, suas ideias foram tomadas por muitos reformadores, entre eles pelo prefeito do Rio de Janeiro, Pereira Passos.

13 Sobre esse processo de mudanças pelo qual passavam muitas cidades brasileiras, ver CHALHOUB, 2001; RAGO, 1985, entre outros. A preocupação com a necessidade de disciplinar a mão de obra ultrapassava o âmbito municipal e chegava até o governo do estado. São recorrentes às menções ao combate à vadiagem. Ver por exemplo, a Mensagem do Presidente do Estado de Minas Gerais de 1901, onde era defendido o vigoroso combate à mesma (p. 16). 
Rio de Janeiro, reformar o espaço urbano significava construir o mundo burguês. Para tanto era necessário incorporar serviços como o abastecimento de água e a iluminação pública.

Essas transformações sustentavam-se pela posição de Uberaba no circuito comercial que ligava litoral e interior. Grande parte dos esforços dos membros da Câmara Municipal centrava-se na manutenção de estradas que ligavam a cidade a outras importantes regiões, como o sul de Goiás. Houve o esforço conjunto visando que as cidades importantes do sul goiano se ligassem a Uberaba, para que a urbe mineira concretizasse o seu papel como centro comercial que irradiava a sua influência até o interior do Brasil (Oliveira, 2014, p. 58).

\section{Os vetores da modernização uberabense}

O processo de modernização da cidade de Uberaba era guiado por boiadeiros, criadores e comerciantes que compartilhavam a direção política local. Apesar de alguns terem a ênfase de seus negócios em determinados momentos em uma das atividades colocadas, há que se atentar para o fato de que os homens e mulheres do meio do caminho possuíam atividades diversas. Comerciantes possuíam terras, e fazendeiros se envolviam no comércio. Aproveitavam as oportunidades que lhes eram oferecidas. Nesse grupo, conviveram em Uberaba Gabriel Orlando Teixeira Junqueira e Rosa Maria de Oliveira.

Gabriel Orlando Teixeira Junqueira possuía o sobrenome de uma família importante, dona de negócios que iam desde o interior do Brasil até a cidade de Santos, passando pela importante região produtora de café de Ribeirão Preto. Nasceu na Fazenda das Melancias, em Uberaba, filho do Coronel João Francisco Diniz e de Francisca Angélica; descendia do Barão de Alfenas, fato referido em diferentes documentos, o que conota que àquela altura Gabriel, um Junqueira, desfrutava do capital político acumulado pela família. Os Junqueiras têm como seu local de origem Carrancas, localidade próxima à cidade de São João del-Rei, em Minas Gerais. A partir da segunda geração seus membros passaram ocupar regiões afastadas de seu centro irradiador, em busca de novas terras. Essa dispersão fez com que ao final do século XIX e início do XX os Junqueiras se encontrassem, além do Triângulo Mineiro, em regiões como Goiás, Rio de Janeiro e o 
Nordeste Paulista (Andrade, 2014, p. 238). ${ }^{14}$ O Barão de Alfenas, também chamado Gabriel, era o filho mais novo do casal fundador e exerceu importante papel político na província de Minas Gerais na primeira metade do século XIX.

No momento em que a esposa de Gabriel Orlando Teixeira Junqueira faleceu, em 1898, os bens do casal incluíam terras em Minas Gerais e em São Paulo, parte herdadas do pai de Gabriel Orlando. Possuía fazenda equipada, produtora de café, com 70 mil pés e máquina de beneficiar com capacidade para 600 arrobas por dia, além de engenho de produção de fubá. ${ }^{15}$

Quadro 1 Alguns bens constantes no inventário de Carolina Teixeira Machado Junqueira, 1898

\begin{tabular}{l|r}
\hline Bens imóveis em Uberaba & Valor (Rs.) \\
\hline 1 terreno urbano & $100 \$ 000$ \\
\hline 1 chácara & $25: 000 \$ 000$ \\
\hline 1 casa pequena & $1: 500 \$ 000$ \\
\hline 1 casa & $1: 500 \$ 000$ \\
\hline 1 casa grande & $3: 708 \$ 000$ \\
\hline Bens imóveis em Sacramento & Valor (Rs.) \\
\hline Fazenda Lageado - Lucilia J. Machado & $99: 495 \$ 900$ \\
\hline Fazenda Lageado - Alice M. Junqueira & $99: 495 \$ 900$ \\
\hline Fazenda Lageado - Gabriel 0. T. Junqueira & $201: 008 \$ 199$ \\
\hline Bens imóveis em Franca & Valor (Rs.) \\
\hline 1 parte de terras de culturas e campos & $3: 707 \$ 994$ \\
\hline
\end{tabular}

Fonte: Inventário de Carolina Teixeira Machado Junqueira, Uberaba, 1898. APU, Segunda Vara Civil, caixa 312.

O monte mor do inventário alcançou o valor de Rs. 513:845\$394, composto por bens imóveis no valor de Rs. 435:515\$994, semoventes avaliados em Rs. 25:220\$000, dívidas no valor de Rs. 51:309\$400 e móveis que alcançavam Rs. 1:800\$000. As terras com melhor avaliação estavam em Sacramento, próximas à estação da Conquista da CMEF. Alcançavam aproximadamente o valor de Rs. 400:000\$000. Contavam com significativas benfeitorias: a parte que coube a Gabriel Orlando na divisão possuía

14 Sobre a ocupação do nordeste paulista, ver: CUNHA, 2010, além de BACELAR; BRIOSCHI, 1999.

15 Inventário de Carolina Teixeira Machado Junqueira, Uberaba, 1898. APU, Segunda Vara Civil, caixa 312. 
170 mil pés de café, máquinas para beneficiar, 20 casas duplas para 40 famílias de colonos, terreiro de secar café com lavador e casa de vigia, casa de morada com latrinas de esgoto até o córrego, currais de aroeira, pastos cercados com capim, invernadas, além de currais e carros de bois. As terras no estado de São Paulo ficaram para as herdeiras. O gado do casal estava concentrado na comarca de Sacramento. À parte as benfeitorias, o que fazia com que as terras de Sacramento alcançassem aquele valor era a sua proximidade com a estação da CMEF, fato reiterado a todo momento quando elas eram citadas. A existência de carros de bois poderia significar o transporte dos produtos da fazenda até a estação por meio destes.

A maior parte de seu patrimônio estava claramente concentrada em imóveis, alcançando $85 \%$ do montante. Desses, os mais valiosos eram os rurais. Em seguida vinham as dívidas a receber, com menos de $10 \%$, os semoventes e, por fim, os móveis.

Nas primeiras legislaturas do período republicano Gabriel Orlando Teixeira Junqueira foi o intendente municipal de Uberaba, o vereador que coordenava os trabalhos da Câmara Municipal. Foi sob seu comando, compartilhados com outros membros de relevo da sociedade uberabense, que muitas das ações de modernização e de urbanização foram concebidas e colocadas em prática. A atuação de Gabriel Orlando Teixeira Junqueira se valia do capital político e econômico acumulados por sua família, ao mesmo tempo que expressava a reprodução de estratégias utilizadas pelos seus antecessores. Desde sua ascensão na região de Carrancas, a família Junqueira baseava sua prática no tripé família, política e negócios (Andrade, 2014, p. 266).

Os vínculos dos comerciantes locais com o mercado interior e com a economia exportadora adquiriam diversas configurações. Os homens de negócio da região de Uberaba, com negócios não especializados, dedicavam-se a diferentes funções, relacionando-se com a intermediação comercial, com a criação e intermediação de gado, venda e compra de terras, e o que mais tornasse atraente o investimento de seus capitais, não só em sentido econômico, mas também o capital político e o derivado de suas redes de influência.

Gabriel Orlando Teixeira Junqueira, no período em que residiu na região de Uberaba, envolveu-se em diferentes negócios ligados a transações de imóveis urbanos e rurais. Em 1894 os Junqueiras de Uberaba negociaram a compra e venda de terras com os Junqueiras de São Paulo. A procu- 
ração feita para que o negócio fosse concretizado foi assinada na casa de Gabriel Orlando Teixeira Junqueira. Na ocasião, João Malachias Junqueira e sua esposa, Maria Augusta Teixeira Junqueira, moradores da cidade de São Simão, no estado de São Paulo, venderam a José Américo Teixeira Junqueira, residente na cidade de Uberaba, uma parte de terras de culturas e campos na fazenda das Melancias, além de parte de terras na Ilha Grande ou do Junqueira. ${ }^{16}$ A atuação de Gabriel Orlando como advogado também lhe rendia relações com o interior. Em diferentes momentos foi designado como procurador para representar moradores do estado de Goiás em negócios que possuíam na região de Uberaba. ${ }^{17}$

Não eram só os Junqueiras que possuíam negócios que ultrapassavam as fronteiras entre Minas Gerais e São Paulo. Havia um significativo movimento de compra e venda de terras envolvendo uberabenses e habitantes do lado sul do Rio Grande, de cidades como Batatais, Franca, Jaboticabal etc. Chamam a atenção os negócios que se estabeleceram entre uberabenses e áreas importantes na criação ou intermediação de gado. Em 1892, Silvestre Bernardes de Oliveira cobrou dívida de Alexandre do Carmo e Silva, residente em Jataí, estado de Goiás. $\bigcirc$ valor do crédito não foi especificado. ${ }^{18}$ Outro crédito foi cobrado por Joaquim Simões de Lima no interior de Goiás, em Meia Ponte e Corumbá, representado por Clarimundo Simões de Lima, em 1894. ${ }^{19} \bigcirc$ mesmo Joaquim Simões de Lima possuía terras em Passos, Minas Gerais, tidas por herança. ${ }^{20}$ Manoel Antônio Gonçalves Chaves, com filhos em Uberaba, possuía terras em Barretos, vendidas por eles após a sua morte, em 1894. ${ }^{21}$

Rosa Maria de Oliveira e seu marido, José de Oliveira Ferreira, representavam outra das engrenagens que ligavam a economia interior à economia exportadora a partir de Uberaba. ${ }^{22}$ Quando ela faleceu na cidade, em 1920,

16 Livro de registros cartoriais do Segundo Ofício de Uberaba, n. 24, de 1914. p. 3, 4.

17 Esse foi o caso de José Pará e Maria Joaquina Pará, residentes em Jataí, estado de Goiás, representados por Gabriel Orlando Teixeira Junqueira na divisão de terras na comarca de Ponte Alta. Também em 1891 Gabriel Orlando Teixeira Junqueira foi responsável, junto com Borges de Araújo, por representar os interesses de um morador de Rio Verde em Uberaba (Livro 18, de 1891).

18 Livro de registros cartoriais do Segundo Ofício de Uberaba, n. 21 de 1892. p. 63.

19 Livro de registros cartoriais do Segundo Ofício de Uberaba, n. 28, de 1894 a 1895. p. 44.

20 Livro de registros cartoriais do Segundo Ofício de Uberaba, n. 23, de 1893 a 1894, p. 8.

21 Livro de registros cartoriais do Segundo Ofício de Uberaba, n. 24, de 1894, p. 99.

22 O inventário de Rosa Maria trata dos bens do casal e não torna possível esclarecer questões como o processo de acumulação desses bens ou o papel de Rosa Maria em sua admi- 
Gabriel Orlando já havia desdobrado a sua atuação para a cidade de Santos, onde passou a se dedicar à exportação de café. Era de nacionalidade portuguesa, nascida na cidade de Oliveira. No ano anterior à sua morte, no seu $81^{\circ}$ aniversário, redigiu testamento por meio do qual deixou para os pobres de sua cidade de origem parte dos bens que havia acumulado durante a vida, mas não foi atendida pelos herdeiros, os quais alegaram a sua insanidade para não cumprirem o seu último desejo. Não foi possível precisar o momento de sua chegada à cidade triangulina, onde desenvolveu diferentes atividades. Teve cinco filhos, um deles já falecido àquela altura. Seus negócios ultrapassavam os limites de Minas Gerais e chegavam até os estados de Goiás e Mato Grosso. Possuía terras de criar, com cabeças de gado em ambos, além de terras de culturas.

O gado mato-grossense, por ser criado em sociedade, não chegou até a partilha no processo de inventário. Sobre as propriedades goianas temos interessantes informações: ao falecer, Rosa Maria de Oliveira possuía no estado central várias partes de terras e gado. Possuía 220 vacas, 86 bezerros, 53 garrotes, 11 touros e 30 novilhos bravos. Como a maior parte do gado goiano, o de propriedade de Rosa Maria de Oliveira também podia seguir por terra ou ferrovia rumo aos mercados consumidores paulistas, o que se reforça pelo fato de, ao falecer, Rosa Maria de Oliveira também ter deixado partes de terra de invernada no arraial de Veríssimo, próximo à Uberaba. As terras se localizavam na fazenda que levava o mesmo nome que o arraial, com 80 alqueires, aproximadamente, contando com capim em quase toda a sua extensão. Possuía também outra parte de terra plantada com capim no distrito de Uberaba.

Tirados os custos do processo, o montante dos bens a serem repartidos chegou ao valor de Rs. 756:694\$110. Os bens correspondentes às partes de terras em Goiás e Mato Grosso, tal como o rebanho, ficaram para o marido José de Oliveira Ferreira: a parte de terras na fazenda Veríssimo, próxima a Uberaba, avaliada em Rs. 20:000\$000, uma parte de terras também de invernadas na fazenda Ressaca, no mesmo distrito, avaliada em Rs. 22:000\$000; uma parte de terras de campos e brejos na mesma fazenda,

nistração. Contudo, por ser seu inventário e não de seu marido, traz informações específicas sobre ela, como a sua origem e seu vínculo com a região portuguesa da qual era originária. Rosa Maria poderia ter mantido vínculos comerciais com Portugal, da mesma maneira que seus conterrâneos analisados a seguir. A abordagem aqui estabelecida não considera Rosa Maria como pioneira, chefe dos negócios familiares. Mesmo assim, era parte importante e integrante desse circuito comercial. 
avaliada em Rs. 5:000\$000; uma parte de terras com 1.390 alqueires em Rio Verde, Goiás, avaliada em Rs. 6:000\$000, um sítio com casa de morada no mesmo local, avaliada em Rs. 4:000\$000, uma parte de terras de campos em matas na mesma localidade, por Rs. 30:000\$000, uma chácara no estado do Mato Grosso, avaliada em Rs. 5:000\$000, dois terrenos urbanos em Uberaba por Rs. 1:000\$000, além de uma empresa de água potável em Uberaba avaliada em Rs. 40:000\$000, 933 cabeças de gado e algumas dívidas a receber. As demais dívidas a receber foram repartidas entre os outros herdeiros. Como se nota os negócios mais importantes e lucrativos ficaram para o chefe do núcleo familiar. ${ }^{23}$

Apesar de não aparecerem diretamente relacionados na documentação, foi durante a atuação de Gabriel Orlando na Câmara Municipal de Uberaba que sua trajetória e a de Rosa Maria se cruzaram. Na câmara municipal Gabriel Orlando exerceu seu cargo de vereador ao mesmo tempo que José de Oliveira Ferreira, esposo de Rosa Maria de Oliveira. Ambos foram componentes da empresa responsável pela implementação da iluminação elétrica na cidade. Avançamos ainda mais se notarmos um dos itens deixados por Rosa Maria ao seu marido: uma empresa de abastecimento de água.

Uma empresa de água potável com três caixas para água, encanamentos (...) avaliada em quarenta contos de réis;

Uma caixa d'água no Alto do São Benedito, e pequeno terreno nos fundos da casa de Amálio Luís da Costa, avaliado por quatrocentos mil. ${ }^{24}$

A Lei N. 91, de 8 de junho de 1898, foi mais uma das aprovadas durante a atuação de Gabriel Orlando como intendente municipal. Por ela, foram autorizados os estudos para o abastecimento de água da cidade (Bilharinho, 2007, p. 63).

Além de Rosa Maria, os documentos revelaram a existência de um significativo grupo de comerciantes de origem portuguesa que mantinha vínculos com o comércio local e com as regiões de onde provinham. ${ }^{25}$ Dois representantes desse grupo são João Gomes de Oliveira e Silvestre Bernardes de Oliveira. Apesar do mesmo sobrenome, não há como afirmar por meio das fontes analisadas se possuíam algum grau de parentesco com 23 Inventário de Rosa Maria de Jesus, Uberaba, 1920. APU, Segunda Vara Civil, caixa 339. 24 Inventário de Rosa Maria de Jesus, Uberaba, 1920. APU, Segundo Vara Civil, caixa 339. 25 Chalhoub (2001) destacou a ação dos comerciantes portugueses na cidade do Rio de Janeiro no início da República, as relações que estabeleciam entre eles e com os demais grupos. Lá, como em Uberaba, os imigrantes portugueses formavam laços de solidariedade entre si, o que os ajudava em suas relações comerciais e de trabalho. 
Rosa Maria. Oliveira era, como hoje, um sobrenome comum. João Gomes e Silvestre foram encontrados no Livro de registros cartoriais do Segundo Ofício de Uberaba, n. 21, 1892.

João Gomes de Oliveira, José Gomes de Oliveira e Luciano Gomes Machado, assinaram em 22 de fevereiro de 1893 procuração para serem representados pelo pai de ambos, Jerônimo Gomes de Oliveira, em negócios em Portugal, em localidade próxima a Coimbra, no conselho de Castanhede. A procuração dizia respeito à compra e venda de bens de raiz, móveis e semoventes, ao recebimento de doações, cobrança e recebimento de títulos, além de outras providências necessárias. Ao que parece os uberabenses de origem portuguesa possuíam estreita ligação com a região de Castanhede. No mesmo ano, Antônio Machado assinou procuração para ser representado no mesmo conselho por João Barreiro, lá residente. O outorgado deveria tratar de questões ligadas ao inventário e partilha dos bens de sua mãe, Francisca Ferreira, viúva do finado Joaquim Machado. ${ }^{26}$ Os vínculos familiares que poderiam sustentar laços comerciais ultrapassavam o oceano. José Constantino vivia em Uberaba em 1894, ao mesmo tempo que sua esposa continuava a residir em Portugal. Na ocasião, ambos apareciam negociando um imóvel na cidade. ${ }^{27}$

João Gomes de Oliveira, português proveniente de Castanhede, era diretor de linha da CMEF. Esse cargo, junto com a sua rede familiar que se desdobrava para além do oceano, lhe garantia relações privilegiadas. Era ele, por exemplo, o responsável pela compra de dormentes para a ferrovia. $O$ atributo de escolher de quem iria adquirir o material certamente lhe rendia a possibilidade de relacionar-se com algumas personalidades locais importantes, como Gabriel Orlando Teixeira Junqueira. Falecido em 1894, João Gomes tinha entre os credores de seu espólio Gabriel Orlando, o qual aparecia cobrando uma dívida referente ao fornecimento de dormentes para a ferrovia. Curiosamente, como ficou registrado, a cobrança dessa dívida de 834\$250 não se baseava em documentos reconhecidos por ambas ou por uma das partes, mas simplesmente no amplo conhecimento dessa transação. Além de chefe de linha da ferrovia, João Gomes também se dedicava à atividade de guardar o dinheiro alheio, como aparece em várias de suas cobranças póstumas. Por exemplo, Antônio Araújo cobrou 
quinhentos mil réis do espólio, referentes ao "dinheiro que tinha posto em suas mãos para guardar". ${ }^{28}$

Todas as cobranças, exceto a de Gabriel Orlando, que não teve a preocupação em documentar-se, buscavam legitimidade recorrendo a um livro que o falecido mantinha e onde registrava todas as transações das quais tomava parte. As dívidas cobradas de seu espólio ultrapassaram o valor de 45:000\$000, significativa para alguém que possuía alguns poucos bens rurais e urbanos. Talvez o seu maior ativo fossem as suas relações.

No caso uberabense, uma parcela significativa dessas redes de comércio se caracterizava pelos arranjos familiares. Há, contudo, de se destacar outro aspecto: além dos laços sanguíneos, a nacionalidade aproximava as pessoas que mantinham diferentes negócios geograficamente dispersos. Os portugueses residentes em Uberaba, além de se encontrarem no meio do caminho entre a economia exportadora e o mercado interior, estavam na intersecção entre diferentes grupos de identificação possíveis. ${ }^{29}$ Rosa Maria era portuguesa, mas também era comerciante. Era peça componente da elite local, com a qual mantinha negócios. Não bastaria ser portuguesa para participar desse circuito comercial. Foram várias características construídas dentro de uma trajetória que tornaram possível o seu enquadramento nesse contexto. Sem descartar suas outras características, o parentesco jogava papel importante. Desde épocas coloniais, a identificação familiar foi responsável pela criação de laços de solidariedade que sustentaram diferentes práticas. ${ }^{30} \mathrm{~A}$ mesma análise pode ser feita com relação a Gabriel Orlando. Junqueira servia-se de laços familiares para concretizar transações importantes, como a compra e venda de terra ou a representação de interioranos, a qual the rendia laços que poderiam ser explorados econômica ou politicamente. Não é também especulação pressupor que o seu sobrenome lhe abria portas para a atuação em outras esferas, como na Câmara Municipal de Uberaba, ou mesmo na obtenção de crédito. Cabe destacar que o comércio sustentado por redes familiares possui grande importância em regiões com um mercado pouco desenvolvido (Casson; Lee, 2011, p. 9-37).

28 Inventário de João Gomes de Oliveira, Uberaba, 1894. APU, Segunda Vara Civil.

29 Pierre Bourdieu (2011) analisa como um indivíduo pode se encontrar na intersecção entre diferentes grupos de representação e como se identifica com eles em momentos e situações específicas.

30 Ver: FARIA, 1998. 
Dentro da lógica institucional dos Estados Unidos do Brasil, tanto os negócios de Gabriel Orlando e os Junqueiras, quanto os de Rosa Maria e comunidade portuguesa, ultrapassavam fronteiras. Os estados dentro do arranjo da Constituição de 1891 possuíam larga autonomia política e econômica. O poder, de fato, ultrapassava o arranjo constitucional e tornava possível que em alguns casos os estados agissem como amplamente autônomos, construindo verdadeiras barreiras comerciais entre si. O café de Gabriel Orlando, produzido em Uberaba, passava por São Paulo e dependia de uma negociação entre governos que ultrapassava o seu raio de ação (Love, 1993, p. 186). O mesmo ocorria com o gado de Rosa Maria. ${ }^{31}$

Rosa Maria e Gabriel Orlando, únicos em suas trajetórias, ao mesmo tempo eram representativos de um importante comércio que ultrapassava a cidade de Uberaba e era ali potencializado. Grande parte desse dinamismo tinha origem em sua localização geográfica e na ferrovia que, tomando emprestadas as palavras de Paulo Roberto Cimó Queirós (Queirós, 2004), ligava dois mundos - a CMEF continuada pela EFG conectava a dinâmica economia paulista à economia goiana, importante, mas caracterizada por um ritmo, ou um tempo diferente, se seguirmos uma abordagem braudeliana.

Os dados da CMEF para o Triângulo Mineiro ajudam a construir um quadro sobre o comércio que por ali passava (Gráfico 1).

O gado possuía grande importância para os uberabenses. Era o produto mais citado nas fontes quando se tratava de diferentes assuntos. Num primeiro momento, Uberaba se apresentava como intermediadora. Mais tarde, a partir do início do século XX como criadora, devido à ação dos fazendeiros locais que ali implementaram a criação do gado indiano (Rezende, 1991; Medrado, 2013). A passagem de gado por Uberaba respondia à demanda do complexo cafeeiro, não só mercado consumidor imediato, mas responsável pelo processamento e exportação da carne. Esse expediente se mostrou mais intenso durante a Primeira Guerra Mundial, quando os mercados mundiais se fecharam ao café e forçaram, por conseguinte, a economia paulista a buscar um novo espaço, ainda que temporário, no mercado dos países em guerra (Fritsch, 1990; Suzigan, 1986).

31 Lopes; Riguzzi (2012) desenvolveram interessante trabalho sobre o comércio de gado entre o México e os Estados Unidos no início do século XX. Nesse trabalho, analisaram os aspectos políticos que influenciaram esse comércio e sua importância para os dois países. Assim como em São Paulo, nos Estados Unidos o gado servia à indústria de carnes, ao contrário do México, fornecedor do produto, onde a criação continuava extensiva. 


\section{Gráfico 1 Movimentação de animais no Ramal Catalão até 1923, em cabeças}

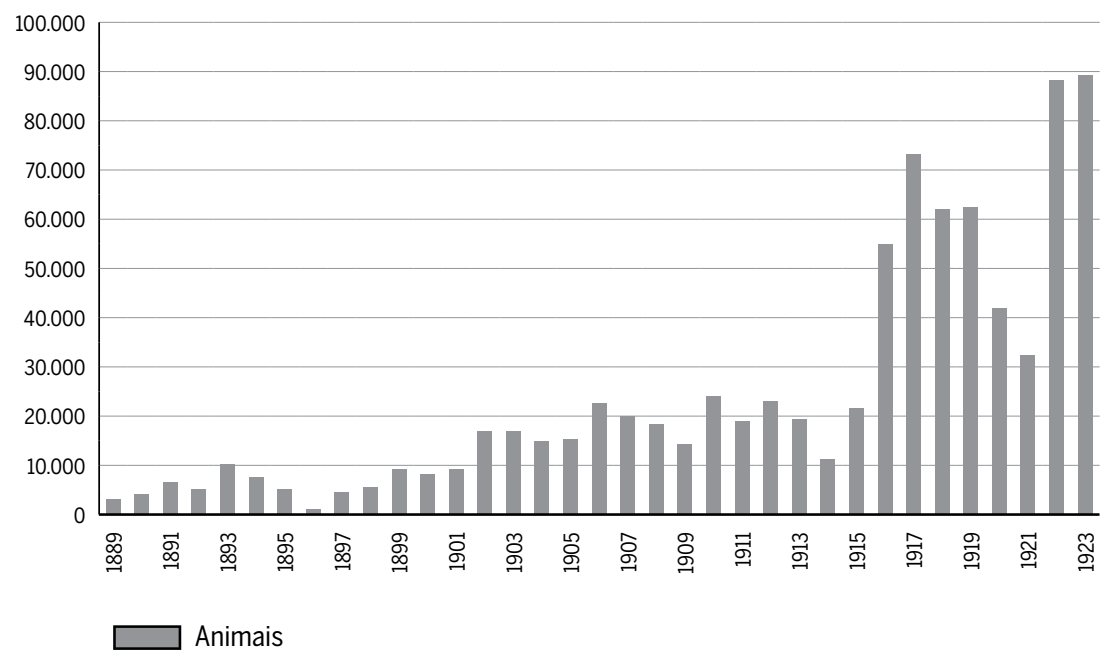

Fonte: Relatórios para aprovação na Assembleia Geral da Companhia. Mogiana, 1890-1924.

Obs.: Os dados apresentados somam importações e exportações para cada ano.

Há também uma movimentação considerável de produtos diversos, constituídos principalmente por itens ligados ao comércio:

\section{Gráfico 2 Movimentação de produtos diversos no Ramal Catalão da CMEF, em toneladas}

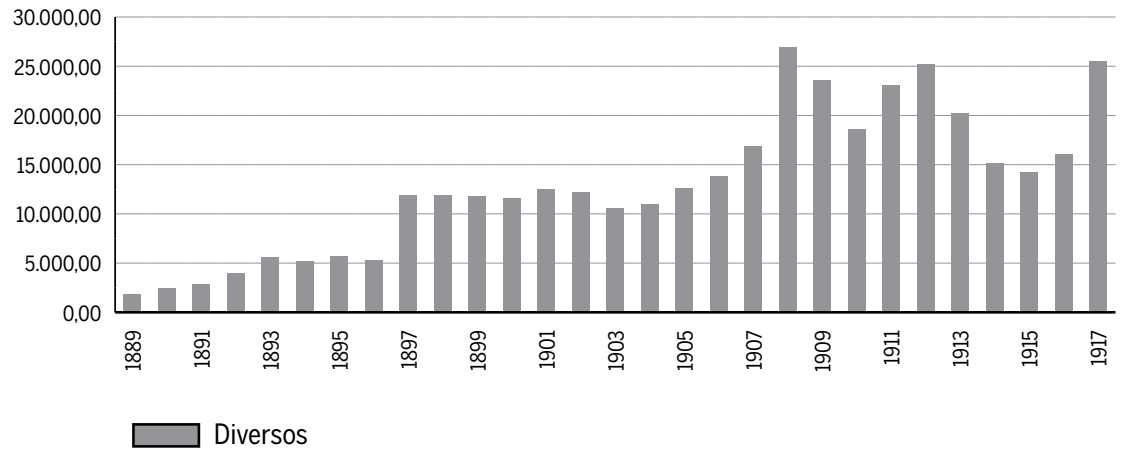

Fonte: Relatórios para aprovação em Assembleia Geral, 1890-1918.

Obs.: Os dados do tráfego se referem às importações mais exportações para cada ano.

Entre os produtos diversos provavelmente estavam aqueles que eram encaminhados ao comércio e que, após deixarem as lojas por sobre os 
balcões dos comerciantes, constituíam o patrimônio que era descrito nos inventários e que denotavam o acesso de uberabenses - de uma parcela modesta - a produtos que caracterizavam a reprodução de um padrão de consumo moderno, passível de ser sustentado por poucos àquela altura.

Rosa Maria e Gabriel eram engrenagens desse comércio, privilegiados por se encontrarem no meio do caminho entre a economia exportadora e o mercado interior. No momento em que Rosa Maria encheu seus pulmões pela última vez com os ares do Triângulo Mineiro, quando cerrou seus olhos pela derradeira vez, Gabriel Orlando Teixeira Junqueira já havia estendido a sua atuação até a cidade de Santos, onde passou a dedicar-se aos negócios de exportação de café.

Gabriel Orlando transitava pelo circuito do Anhanguera. Além dos investimentos no núcleo urbano de Uberaba e na região, Gabriel Orlando também, já ao início do século XX, atuava na cidade portuária de Santos, no litoral paulista. Em 1901 a Junqueira, Guimarães, Leitão e Cia. era uma casa comercial de destaque na cidade de Santos, formada por José Frauzino Junqueira Netto e coronel Francisco Orlando Diniz Junqueira, de Orlândia; dr. Antônio Torquato Fortes, José Manuel de Azevedo Marques e capitão Henrique Luiz de Azevedo Marques, de Nuporanga; dr. Gabriel Orlando Teixeira Junqueira, de Conquista; coronel Joaquim da Cunha Diniz Junqueira, de Ribeirão Preto; Francisco Gomes Leitão, de Cravinhos, e Francisco Marcos Inglês de Souza, de Itapira. Mais tarde a sua denominação foi alterada para Junqueira, Netto \& Cia., sob a direção de José Mário Junqueira Netto (Bacellar; Brioschi, 1999, p. 134). ${ }^{32}$

Em 25 de Junho de 1921, entre os atos do Poder Executivo paulista, constava a nomeação de Gabriel Orlando para o cargo de Presidente da Bolsa Oficial de Café e da Câmara Sindical dos corretores de Santos. A Bolsa Oficial do Café de Santos foi criada em 1914 pela lei do estado 1.416 , de 14 de junho. A criação de uma bolsa do café era estudada pelo governo paulista desde 1906. A sua instalação ocorreu em 2 de maio de 1917, em um salão alugado que logo se tornou insuficiente para as negociações. Gabriel Orlando Teixeira Junqueira foi seu segundo diretor, após Adelino de Almeida Prado. Os presidentes da Bolsa eram eleitos anualmente entre os corretores de café de Santos e possuíam como um de seus

32 Sobre a importância do porto de Santos, cabe destacar que no período entre guerras ele já alcançava as regiões do Sul de Minas, Triângulo Mineiro, sul de Goiás e Mato Grosso, além do norte do Paraná. Ver ARAÚJO FILHO, 1969, p. 74. 
objetivos centralizar e sistematizar as operações de comércio de café, estabelecer normas e regulamentos para essas operações, apurar, registrar e divulgar a cotação do produto. ${ }^{33}$

\section{Considerações finais: Rosa e Gabriel entre a econo- mia interna e a economia exportadora}

Em 1898, ainda na primeira década do regime republicano, Gabriel Orlando Teixeira Junqueira enterrou a sua esposa, Carolina Teixeira Machado Junqueira. Da união de ambos ficaram duas filhas e um patrimônio que envolvia imóveis urbanos e rurais, entre os quais ganhava destaque uma fazenda de café. O café e os seus desdobramentos seriam presentes na trajetória de Gabriel Orlando. Após a morte de sua esposa, seguiu, continuou a ser figura importante da elite local e conseguiu se alçar ao importante posto de presidente da Bolsa do Café de Santos na década de 1920.

No início dessa última década faleceu na cidade de Uberaba Rosa Maria de Oliveira, portuguesa, com negócios que se estendiam desde as regiões centrais do Brasil até Uberaba. Em conjunto com o marido criava gado em Mato Grosso e Goiás, provavelmente destinados ao mercado paulista, sobretudo após a inauguração do frigorífico de Barretos, o primeiro do Brasil (Perinelli Neto, 2009). Além disso, agia em negócios de melhoramentos urbanos e possuía uma longa lista de dívidas a receber. Era representante de um grupo que se tornou relevante na Uberaba das primeiras décadas do século XX: os portugueses.

São duas histórias que se cruzaram no meio do caminho, entre a economia exportadora e a economia interna em desenvolvimento - ou o mercado interno, como também poderíamos dizer. Rosa e Gabriel eram feixes de um comércio que passava por Uberaba em ambas as direções, comércio esse em grande parte baseado no gado, tendo-o como produto, como moeda de troca, ou como força motriz da economia da região. O complexo cafeeiro em Uberaba não deixava de se basear no café, mas se diversificava; o café continuava a ser o produto principal, cultivado ao sul do rio Grande. Em Uberaba o complexo potencializava-se na ligação com a economia interior. 
Nesse processo, a cidade de Uberaba expandiu sua influência e se especializou na criação de gado, sem abandonar de todo o comércio. Modernizou-se por meio da transformação do espaço urbano, pela chegada de produtos provenientes de São Paulo ou da Europa e pela expansão de negócios que buscavam valer-se do contato com o litoral e com o sertão, por meio de redes familiares ou baseadas na nacionalidade, entre outras.

Nas palavras de Barros de Castro:

\begin{abstract}
Ao se volumar a demanda de alimentos, animais de tração, etc., pelo setor exportador, poderiam chegar a constituir-se autênticas regióes primário-exportadoras internas. Haja ou não processo de individualização das atividades que abastecem o setor exportador, seu funcionamento poderia ser caracterizado como sub-reflexo, por espalhar, indiretamente, as vicissitudes do mercado internacional (Castro, 1969).
\end{abstract}

Outros autores, como Barickman (2003) em O contraponto baiano, tratam dessas relações entre uma economia exportadora e uma região que se especializa na produção de bens para esta. Não sendo São Paulo uma ilha, como bem afirma Wilson Cano (1977), existiu essa relação com as regiões interioranas, onde obteve gado e cereais, entre outros produtos. Alguns autores tratam essa expansão da economia paulista como impositiva. Era hierarquizadora, de fato, mas pode-se notar pelo caso de Uberaba, e por outros mais, como Goiás, explorado em outro trabalho, que os grupos dirigentes das regiões tocadas pelo complexo cafeeiro ansiavam por isso e retiveram parte dos dividendos quando essa ligação se concretizou. Os negócios de Rosa Oliveira e Gabriel Junqueira eram possíveis, em grande parte, por esse contato. A modernização da cidade de Uberaba e de outras no circuito do Anhanguera também. Pode-se arriscar que o complexo cafeeiro possuía sotaque mineiro e que a economia cafeeira paulista ao se expandir não permanecia unicamente paulista, ao menos em muitos aspectos.

\title{
Referências
}

ANDRADE, Marcos Ferreira de. Elites regionais e a formação do estado imperial brasileiro. Minas Gerais - Campanha da Princesa (1799-1850). Belo Horizonte, MG: Fino Trato, 2014.

ARAÚJO FILHO, José Ribeiro de. Santos, o porto do café. Rio de Janeiro, RJ: IBGE, 1969.

ARRUDA, Gilmar. Cidades e sertões. Entre a história e a memória. Bauru, SP: EDUSC, 2000.

ATAS da Câmara Municipal de Uberaba, 1880 a 1905. Arquivo Público de Uberaba. 
BACELAR, Carlos de Almeida; BRIOSCHI, Lucila Reis (Org.). Na estrada do Anhanguera: uma visão regional da história paulista. São Paulo, SP: Humanitas, 1999.

BARICKMAN, Bert Jude. Um contraponto baiano: açúcar, café e escravidão no Recôncavo. Tradução Maria Luiza X. de Borges. Rio de Janeiro, RJ: Civilização Brasileira, 2003.

BILHARINHO, Guido. Uberaba: dois séculos de história (dos antecedentes a 1929). Uberaba, MG: Arquivo Público de Uberaba, 2007. v. 1.

BORGES, Barsanufo Gomides. O despertar dos dormentes. Goiânia, GO: UFG, 1989.

BOURDIEU, Pierre. O poder simbólico. Rio de Janeiro, RJ: Bertrand Brasil, 2011.

CAMARGO, José Francisco de. Crescimento da população no estado de São Paulo e seus aspectos econômicos. São Paulo, SP: Faculdade de Filosofia, Letras e Ciências Humanas/USP, 1952.

CANO, Wilson. Raizes da concentração industrial em São Paulo. São Paulo, SP: DIFEL, 1977.

CARVALHO, José Murilo de. A formação das almas. São Paulo, SP: Cia. das Letras, 1997.

CASTRO, Antônio Barros de. 7 Ensaios sobre a economia brasileira. São Paulo: Forense, 1969.

CASSON, Mark; LEE, John. S. The origin and development of markets: A business history perspective. Business Vistor Review, 85, p. 9-37, Spring 2011.

CHALHOUB, Sidney. Trabalho, lar e botequim. O cotidiano dos trabalhadores no Rio de Janeiro da belle époque. Campinas, SP: Unicamp, 2001.

CUNHA, Maísa Faleiros da. Mineiros em terras paulistas. In: XIV SEMINÁRIO SOBRE ECONOMIA MINEIRA. Diamantina, MG: 2010.

FALEIROS, Rogério Naques. Fronteiras do café: fazendeiros e colonos no interior paulista (1917-1937). Bauru, SP: Edusc; FAPESP, 2010.

FARIA, Sheila de Castro. A colônia em movimento: fortuna e família no cotidiano colonial. Rio de Janeiro: Nova Fronteira, 1998.

FRANCO, Maria Sylvia de Carvalho. Homens livres na ordem escravocrata. São Paulo: UNESP, 1997.

FRITSCH, Winston. Apogeu e crise na Primeira República: 1900-1930. In: ABREU, Marcelo de Paiva (Org.). A ordem do progresso: cem anos de política econômica republicana. Rio de Janeiro, RJ: Campus, 1990.

INVENTÁRIO de Carolina Teixeira Machado Junqueira, Uberaba, 1898. Arquivo Público de Uberaba, Segunda Vara Civil, caixa 312.

INVENTÁRIO de Rosa Maria de Jesus, Uberaba, 1920. Arquivo Público de Uberaba, Segunda Vara Civil, caixa 339.

LIVRO de registros cartoriais de Uberaba, 1891, 1892, 1893, 1894, 1895, 1914.

LOPES, Maria Aparecida; RIGUZZI, Paolo. Borders, trade, and politics: Exchange between the United States and Mexican Cattle Industries, 1870-1947. Hispanic American Historical Review 92:4, 2012.

LOVE, Joseph. Federalismo y regionalismo em Brasil, 1889-1937. In: CARMAGNANI, M. (Coord.). Federalismos latinoamericanos: México - Brasil - Argentina. México: Fondo de Cultura Económica, 1993.

MARTINS, José de Souza. O cativeiro da terra. São Paulo: Ciências Humanas, 1979. 
MATOS, Odilon Nogueira de. Café e ferrovias. Evolução ferroviária de São Paulo e o desenvolvimento da cultura cafeeira. São Paulo, SP: Alfa Omega, 1974.

MEDRADO, Joana. Do pastoreio à pecuária. A invenção da modernização rural nos sertões do Brasil Central. 2013. Tese (Doutorado em História) - Instituto de Ciências Humanas e Filosofia, Universidade Federal Fluminense, Niterói, RJ, 2013.

MELLO, João Manuel Cardoso de. O capitalismo tardio. Contribuição à revisão crítica da formação e do desenvolvimento da economia brasileira. São Paulo, SP: Brasiliense, 1998.

OLIVEIRA, Paulo Roberto de. Um caminho voltado para dentro: o circuito goiano e o comércio entre Goiás e São Paulo na Primeira República. Tese (Doutorado em História) - Faculdade de Filosofia, Letras e Ciências Humanas, Universidade de São Paulo, São Paulo, 2014.

PERINELLI NETO, Humberto. Nos quintais do Brasil: homens, pecuária, complexo cafeeiro e modernidade - Barretos (1854-1931). 2009. Tese (Doutorado em História). Faculdade de História, Direito e Serviço Social - Universidade Estadual Paulista Júlio de Mesquita Filho, Franca, SP, 2009.

PESSOA JUNIOR, Diocleciano Ribeiro. Estudo descriptivo das estradas de ferro do Brazil precedido pela respectiva legislação. Rio de Janeiro: Imprensa Nacional, 1886.

QUEIRÓS, Paulo Roberto Cimó. Uma ferrovia entre dois mundos: A E. F. Noroeste do Brasil na primeira metade do século 20. Bauru, SP: EDUSC, 2004.

RAGO, Margareth. Do cabaré ao lar. A utopia da cidade disciplinar. Rio de Janeiro, RJ: Paz e Terra, 1985.

RELATÓRIOS da Companhia Mogiana de Estradas de Ferro, 1890 a 1920. Museu da Companhia Paulista, Jundiaí, SP.

RESTITUTI, Cristiano Corte. As fronteiras da provincia: rotas de comércio interprovincial, Minas Gerais, 1839-1884. 2006. Dissertação (Mestrado em Economia) - Faculdade de Ciências e Letras de Araraquara, Universidade Estadual Paulista Júlio de Mesquita Filho, Araraquara, SP, 2006.

REZENDE, Eliane Mendonça Marquez de. Uberaba 1811-1910: uma trajetória sócio-econômica. Uberaba, MG: Arquivo Público, 1991.

SAES, Alexandre Macchione; FONTANARI, Rodrigo; OLIVEIRA, Paulo Roberto de. O complexo cafeeiro paulista: comércio de café e gado pela Cia. Mogiana E. F. (1900-1920). In: FALEIROS, Rogério Naques; NUNES, Ivanil (Org.). Sistemas de transportes e formações econômicas regionais. Brasil \& Argentina. Vitória, ES: UFES, 2016.

SAES, Flávio Marquez Azevedo de A. As ferrovias de São Paulo (1870-1914). São Paulo, SP: HUCITEC, 1981.

SEVCENKO, Nicolau (Org.). História da Vida Privada no Brasil. São Paulo, SP: Companhia das Letras, 2006.

SUZIGAN, Wilson. Indústria Brasileira. Origem e desenvolvimento. São Paulo, SP: Brasiliense, 1986.

TOSI, Pedro Geraldo; FALEIROS, Rogério Naques. Domínios do café: ferrovias, exportação e mercado interno em São Paulo (1888-1917). Economia e Sociedade. Campinas, v. 20, n. 2 (42), p. 417-442, ago. 2011. 


\section{Sobre o autor}

Paulo Roberto de Oliveira - prohist@gmail.com

Universidade Federal de Ouro Preto, Mariana, Minas Gerais, Brasil. ORCID: https://orcid.org/0000-0001-9198-0718.

\section{Sobre 0 artigo}

Recebido em 17 de setembro de 2017. Aprovado em 16 de fevereiro de 2018. 